\title{
LAS VIVIENDAS PARTICULARES DEDICADAS A LA ACTIVIDAD DE \\ ALOJAMIENTO TURÍSTICO. SU EXCLUSIÓN DE LA LEY DE ARRENDAMIENTOS URBANOS
}

\author{
Alejandro Román Márquez \\ PSITC de la Universidad de Sevilla \\ Email: alejandroroman@us.es
}

Resumen: Durante muchos años los propietarios de viviendas particulares han utilizado el arrendamiento civil para alojar a sus huéspedes temporales, muchos de los cuáles tenían una naturaleza inequívocamente turística, sin ser objeto de ningún reproche de carácter jurídico más allá de cuestiones exclusivamente fiscales. El trabajo realiza un análisis de la reciente modificación de la LAU, que excluye expresamente de esta Ley los alquileres de naturaleza turística.

Abstract: For many years, individual homeowners have used the civil lease to accommodate their temporary guests, many of whom had unequivocally tourist nature, without being subject to any reproach Legal beyond purely fiscal matters. The paper analyzes the recent amendment to the LAU, that this Act expressly excludes tourist vacation nature.

Palabras clave: apartamentos, turismo, arrendamientos urbanos, alquiler vacacional, alojamientos clandestinos.

Keywords: apartments, turism, urbanrentals, holidayrentals, clandestineaccommodation. 


\section{Introducción y justificación del objeto de estudio.}

La justificación del objeto de estudio elegido para el presente artículo, cuyos límites quedan explicitados en su título, está conformada por dos circunstancias. La primera de ellas por ser las viviendas particulares la modalidad de alojamiento turístico "clandestino" o al margen de la normativa turística (que no ilegal) con más importancia desde el punto de vista cuantitativo. Sin desconocer que existen otras modalidades de alojamientos turísticos que pueden operar al margen del control administrativo ( $v . g r$. alojamientos rurales o campings), su incidencia desde el punto de vista económico y social es menor, lo que justifica su exclusión del objeto de estudio. En segundo lugar, la modificación operada recientemente en la normativa sobre arrendamientos urbanos aconseja un tratamiento pormenorizado de este fenómeno, con el objetivo de clarificar en lo posible la situación actual y adelantar su probable evolución en el futuro inmediato $^{1}$.

A diferencia de lo que ocurre en otros países, como por ejemplo en ciertos estados iberoamericanos (V.gr. Colombia), en el entorno europeo todos los establecimientos de alojamiento turístico deben cumplir con los requisitos que administrativamente se determinen y estar debidamente inscritos en el correspondiente registro público. En tal sentido, el Ordenamiento Jurídico español establece tanto las características mínimas (infraestructura, seguridad, sostenibilidad, confortabilidad, servicios, etc) de todos los

\footnotetext{
${ }^{1}$ Sobre establecimientos de alojamiento turístico al margen de la legalidad vid., entre otros, BETCH SERRAT, J. M ${ }^{\mathrm{a}}$., "La contratación de apartamentos turísticos: especial referencia al Decreto catalán 163/1998, de 8 de julio, de Apartamentos Turísticos", en Consultor inmobiliario: Revista mensual de actualidad para profesionales, $\mathrm{n}^{\circ}$ 49, 2004, págs. 3 a 16; SOLSONA MONZONíS, J., "Los apartamentos turísticos", en La actividad turística española en 2008 (edición 2009), López Olivares, D. y Pulido Fernández, J. I. (Coords.), AECIT/Editorial Universitaria Ramón Areces, 2009, págs. 141 a 155; SANCHO COMINS, J., REINOSO MORENO, D. y JIMÉNEZ GIGANTE, F. J., "Viviendas de ocupación temporal en la sierra norte de Guadalajara: de su anterior función residencial-agraria a la actual recreativo-turística”, en Serie Geográfica, Universidad de Alcalá, Departamento de Geografía, no ${ }^{\circ}$, 2007-2008, págs. 179 a 192; y PASTOR ÁLVAREZ, Ma C., "Apartamentos turísticos y alojamientos vacacionales en la región de Murcia”, en Anales de economía aplicada 2007, Vol. II, Rojo García. J. L. (Dir.)., Asociación Española de Economía Aplicada, 2007, págs. 89 a 109.
} 
establecimientos de alojamiento turístico como su categorización, otorgada por la Administración pública ${ }^{2}$. No existe, pues, oferta turística alojativa al margen de la regulación administrativa. Con anterioridad a la trasposición al Ordenamiento Jurídico español de la Directiva 126/2006/CE (Directiva de servicios, también conocida como DirectivaBolkestein) era necesario solicitar una autorización administrativa y posteriormente inscribir el establecimiento en el correspondiente registro administrativo para poder iniciar su actividad. Actualmente, como regla general ${ }^{3}$, tanto el inicio del funcionamiento como su inscripción se hacen sobre la base de una "declaración responsable”, revisada a posteriori por la Administración pública. Todo establecimiento turístico que se publicite o realice su actividad sin contar con la preceptiva declaración e inscripción en el registro correspondiente será considerado clandestino, imponiéndosele las sanciones correspondientes ${ }^{4}$.

Junto con este régimen especializado y con vocación de exclusividad, en el ámbito civil la Ley 29/1994, de 24 de noviembre, de Arrendamientos Urbanos (en adelante $L A U)$, ha servido a los propietarios de viviendas particularescomo sustento legal para dedicarlas a la actividad turística. Para ello se ha utilizado tradicionalmente la figura del arrendamiento por temporada, previsto en su artículo 3.2., que dispone que "[...] tendrán esta consideración [arrendamiento para uso distinto de vivienda] los arrendamientos de fincas urbanas celebrados por temporada, sea ésta de verano o cualquier otra,[...]". Por arrendamiento por temporada se entiende, por tanto, el uso de una vivienda que no va a tener carácter permanente, no constituyendo el domicilio del

\footnotetext{
${ }^{2}$ La normativa colombiana no establece un sistema público de categorización de los establecimientos de alojamiento turístico, dejando este cometido -cuya adscripción será en todo caso voluntaria- al buen hacer de las asociaciones privadas del sector. Sobre esta materia, en el ámbito español, vid. PÉREZ GUERRA, R., "La intervención administrativa en la clasificación de los establecimientos hoteleros: estudio comparativo en el Derecho turístico español", en Documentación Administrativa, Presidencia del Gobierno: Gabinete Técnico para la Reforma Administrativa, no 259-260, 2011, págs. 315 a 354.

${ }^{3}$ Regla general que no rige con carácter general en los alojamientos turísticos reglados, si bien parece más que posible su aplicación en el caso de los apartamentos particulares de uso turístico. Sobre esta materia vid. el excelente trabajo del profesor RIVERO YSERN, J. L., "La transposición de la Directiva de Servicios a nivel Autonómico y Local", en El nuevo derecho administrativo: libro homenaje a prof. Dr. Enrique Rivero Ysern, Sánchez Blanco, A., Domínguez-Berrueta de Juan, M. A. y Rivero Ysern, J. L. (Coords.), Ratio Legis Librería Jurídica, Salamanca, 2011, págs. 369 a 406.

${ }^{4}$ Por ejemplo, la Ley 13/2011, de 23 de diciembre, del Turismo en Andalucía, considera como infracción grave la prestación clandestina de un servicio turístico, previendo sanciones que oscilan de los dos mil a los dieciocho mil euros.
} 
arrendatario-la nota esencial es la finalidad del alquiler, y no su duración-, con independencia de que se realice durante el verano o en cualquier otra época del año. Dejando a un lado el controvertido fraude de ley consistente en utilizar esta norma para suplantar la normativa específicamente turística, lo cierto es que durante muchos años los propietarios de viviendas particulares han utilizado esta figura civil para alojar a sus huéspedes temporales, muchos de los cuáles tenían una naturaleza inequívocamente turística, sin ser objeto de ningún reproche de carácter jurídico más allá de cuestiones exclusivamente fiscales. La reciente modificación de la LAU, excluyendo expresamente de esta Ley los alquileres de naturaleza turística, viene a sacudir los cimientos de esta práctica, expulsándola de una vez por todas del ámbito civil, al menos en teoría.

\section{Fundamentos socioeconómicos del aumento de la actividad turística no} reglada y problemas aparejados.

En un entorno económico marcado por la crisis, el turismo, y concretamente su modalidad de sol y playa, es una de las pocas actividades que arrojan un saldo positivo con respecto a ejercicios anteriores. La llegada de turistas extranjeros creció durante el año 2012, previéndose que durante 2013 alcancen la barrera de los sesenta millones de turistas anuales ${ }^{5}$. También el gasto medio por turista ha aumentado con respecto al mismo periodo del año 2012, en torno a un seis por ciento, así como los ingresos por turismo, que han aumentado algo más del dos por ciento ${ }^{6}$. El alquiler de viviendas privadas para uso vacacional se ha convertido en una actividad refugio para profesionales y empresarios de otros sectores en declive, como el inmobiliario, con enormes dificultades para deshacerse de sus activos devaluados, pero también para

\footnotetext{
${ }^{5}$ Por el contrario, el turismo nacional sigue disminuyendo, sin que a mediados de 2013 haya tocado aún fondo. Balance del Turismo. Resultados de la actividad turística en España. Año 2012, Instituto de Estudios Turísticos, Ministerio de Industria, Energía y Turismo, 2013.

${ }^{6}$ Datos del Ministerio de Industria, Energía y Turismo, y Banco de España (balanza de pagos) a julio de 2013.
} 
particulares que necesitan un complemento económico que compense la disminución de sus ingresos, o como único ingreso regular en el caso de desempleados. El éxito de esta actividad reside en su sencillez: únicamente son necesarios un inmueble -e, incluso, parte de éste, como una habitación- y un canal de publicitación, que puede ser tan elemental como el boca a boca o tan efectivo y barato como Internet. Cualquier persona puede participar en esta actividad económica si cumple con estos dos sencillos requisitos, de ahí su extraordinaria popularidad. Por lo que respecta al sector inmobiliario, las dificultades para vender su stock de vivienda nueva le han forzado a realizar un trasvase desde el mercado de venta al de alquiler, y para lo que interesa a este estudio, al mercado de alquiler vacacional, siendo una solución efectiva en el corto y medio plazo para obtener rentabilidad de estos activos.

El alquiler de viviendas particulares para uso turístico arroja unos datos de extraordinaria relevancia, calculándose que alcanza el millón y medio de viviendas dedicadas habitualmente a esta actividad en toda España, generando un negocio de casi dos mil millones de euros (mil quinientos directos y otros quinientos indirectos). De un total de mil cien millones de pernoctaciones turísticas realizadas durante el año 2011, se estima que más de setecientos cincuenta se produjeron en alojamientos turísticos no reglados. La estancia media del turista en este tipo de alojamiento es de siete noches, con un gasto medio diario algo superior a los cincuenta euros. Las Comunidades Autónomas con mayor número de viviendas particulares dedicadas a alquiler turístico son Andalucía, Cataluña y la Comunidad Valenciana ${ }^{7}$. Por lo que respecta al porcentaje de pernoctaciones no regladas en relación con el total de pernoctaciones turísticas, es incluso superior en las Comunidades Autónomas situadas en las dos mesetas, siendo casi del ochenta y siete por ciento en Castilla-La Mancha, ochenta y cuatro y medio por ciento en La Rioja, ochenta y tres y medio por ciento en Castilla y León u ochenta y tres por ciento en Extremadura, frente al casi ochenta por ciento de la Comunidad Valenciana y Región de Murcia, setenta y tres con ocho por ciento de Andalucía y sesenta y cinco con siete por ciento de Cataluña ${ }^{8}$.

\footnotetext{
${ }^{7}$ En ciudades como Barcelona los apartamentos turísticos no reglados llegan a suponer el $10 \%$ de todo su parque de viviendas.

${ }^{8}$ Datos correspondientes a 2012. Anuario Económico de la Caixa 2013.
} 
El desarrollo de esta actividad al margen de la regulación turística genera una serie de problemas, muchos de los cuales han servido como base al legislador para su expulsión del ámbito civil, como se expondrá en el párrafo siguiente. Entre ellos destacan la inexistencia de estándares de calidad, de medidas y controles específicos de seguridad y salubridad para sus usuarios, de registro de huéspedes, que dificulta el trabajo tanto de los cuerpos y fuerzas de seguridad del Estado como de los servicios de estadística, y, lo que es más importante para las Administraciones en el contexto actual de crisis económica, de tributación por parte de los perceptores de estas rentas, que en un alto porcentaje quedan al margen de los ingresos declarados al Fisco. También se ha revelado como un problema en ciertos destinos turísticos la convivencia entre turistas y residentes habituales, ya que la disparidad de horarios y actividades de ambos colectivos hacen muy difícil su conciliación en un mismo inmueble.

\section{Argumentos a favor y en contra de la regulación de este tipo de viviendas.}

La principal razón a favor de su regulación desde el punto de vista exclusivamente turístico tiene que ver con los niveles de satisfacción de la experiencia turística, resultado de la confrontación entre expectativa y realidad. La ausencia de un referente objetivo que proporcione a los usuarios de estos alojamientos unos parámetros de calidad con los que compararlos en el momento de la contratación del servicio, consecuencia de su clandestinidad, puede provocar en numerosas ocasiones que aquéllos se sientan defraudados en sus expectativas al compararlas con la calidad real del alojamiento. Esta circunstancia se reduce al mínimo en el caso de los alojamientos turísticos regulares ya que los diferentes sistemas autonómicos de categorización turística permiten al usuario hacerse una idea bastante fiel de la calidad y servicios de cada uno de los establecimientos de alojamiento turístico que forman parte de la oferta alojativa. La regulación, siquiera superficialmente, de los apartamentos turísticos clandestinos facilita el establecimiento de unos estándares mínimos de calidad, si bien subsiste el problema de su inserción en una categoría concreta que garantice unos 
estándares de calidad, lo que en última instancia puede afectar, por la razón expuesta, a los niveles de satisfacción de los usuarios turísticos. También permite garantizar la veracidad de lo ofertado, permitiendo a la inspección turística controlar que lo publicitado por el prestador de servicios turísticos se corresponde con la realidad, minimizando el impacto negativo que sobre la demanda global tiene la defraudación de las expectativas turísticas.

Otra circunstancia a favor de su regulación administrativa tiene como origen la propia naturaleza jurídica de los contratos de arrendamiento de inmuebles. Si este tipo de arrendamientos se consideran al margen de cualquier actividad turística, su naturaleza es eminentemente civil, como cualquiera de los arrendamientos sometidos a la LAU, lo que excluyela consideración de los arrendatarios como turistas y, por ende, como consumidores. Cualquier controversia que pueda surgir entre las partes deberá sustanciarse en la jurisdicción civil, negando al usuario turístico el acceso a las técnicas privilegiadas que protegen a la figura del consumidor.El arrendatario no tendrá más remedio que acudir a la vía ordinaria civil, con las consecuencias en tiempo y recursos económicos que esto supone, sin contar con la pérdida de una serie de derechos que por su condición de consumidor le son aparejados de forma automática.Esta circunstancia va a influirde forma negativa en los niveles de satisfacción de la experiencia turística, sometiendo al turista a un régimen jurídico que no está pensado para éste y que le perjudica indudablemente. No existe duda acerca de la condición de consumidor que ostenta el turista, por lo que excluirlo de este régimen jurídico afecta negativamente a toda la oferta turística de un determinado destino turístico, en este caso del mercado turístico español en su totalidad. Se produce, en definitiva, una merma en la seguridad jurídica del turista, que afecta muy negativamente a su confianza y, por lo tanto, a las oportunidades reales del destino de ser elegido por éste.

Desde el punto de vista del prestador de este tipo de servicios turísticos, en su condición legal de arrendador sometido a la LAU, no le son aplicables los sistemas sancionadores previstos por la normativa turística, con unas infracciones y unas sanciones predeterminadas. Esto supone que a pesar de prestar un servicio de naturaleza indiscutiblemente turística, queda al margen del régimen sancionador construido por los ordenamientos autonómicos para esta actividad con el objetivo de garantizar los 
derechos de los usuarios turísticos y unos estándares mínimos de calidad. Como en el caso anterior, se hace patente la necesidad de reconducir esta actividad para que su naturaleza y régimen jurídico coincidan.

Otro argumento, estrechamente relacionado con el expuesto anteriormente, aconseja igualmente su regulación administrativa. Si se considera a los arrendatarios de este tipo de inmuebles como turistas y, por lo tanto, consumidores, deberá aplicarse al servicio que arriendan los mismos parámetros generales que a cualquier otro servicio que éstos puedan disfrutar. Estos parámetros generales son los referidos, entre otros, a seguridad estructural, mecanismos contra incendios o salubridad. Los inmuebles arrendados de forma privada a turistas carecen de algunas de estas medidas, al constar oficialmente como viviendas particulares.Parece aconsejable dotar a este tipo de inmuebles de similares medidas de protección de las que disfruta el turista en cualquier establecimiento de alojamiento turístico (insonorización, sistemas de extinción de incendios, señales de evacuación, luminosidad, ventilación, etc), adaptándolas indudablementea la naturaleza de este tipo de inmuebles, que no puede ser la misma que la de un establecimiento hotelero. Por otra parte, y enlazando con la cuestión de la calidad de la experiencia turística, también resulta imprescindible exigir a este tipo de alojamientos unos servicios generales de una calidad mínina, desdelos más esenciales como son los referidos a los saneamientos o materiales constructivos a los más modernos en materia de telecomunicaciones o eficiencia energética. Como en el caso anterior, los niveles de exigibilidad deben estar en consonancia con la naturaleza del alojamiento, algo de lo que parece ser consciente el legislador autonómico, como se analizará en su momento.

Existen, además, otras razones al margen del ámbito exclusivamente turístico, como la necesidad de controlar, desde el punto de vista de la seguridad pública, el flujo de visitantes alojados en estos inmuebles. Cualquier usuario de un establecimiento turístico regular debe facilitar sus datos identificativos esenciales a los responsables del mismo ficha policial-, datos que estarán desde ese mismo instante a disposición de las fuerzas y cuerpos de seguridad del Estado.Este documento se ha demostrado muy útil para la localización de personas buscadas por laJusticia. Los usuarios de apartamento turísticos irregulares se sustraen a este control, lo que puede afectar negativamente a la seguridad 
ciudadana. Existen igualmente razones relacionadas con la opacidad fiscal de estos contratos $^{9}$. Tradicionalmente los contratos de arrendamiento entre particulares han quedado al margen de la fiscalidad. Su consideración como actividad turística puede ayudar a que ésta emerja a la superficie, pero no puede considerarse como una razón de peso para predeterminar su naturaleza turística o como elemento cualitativo en orden a su control tributario, que en todo caso resulta indiferente de cuál sea su naturaleza jurídica-civil o administrativa- en cada momento.

Por último, se ha argumentado que los turistas alojados en apartamentos turísticos irregulares no contribuyen al sostenimiento de los servicios públicos, que disfrutan en plano de igualdad con cualquier turista "legal", lo que contribuye a su saturación y degradación. Resulta imprescindible que las rentas generadas por esta actividad colaboren al mantenimiento de los servicios públicos puestos a su disposición. Sin dejar de ser esto cierto, el problema no se soluciona per se, como en el caso anterior, con la mera inclusión de estos alojamientos en la oferta turística reglada. La eventual clandestinidad de estos usuarios de servicios públicos es independiente de su consideración como arrendatarios por temporada o turistas, por lo que su contribución a las arcas públicas locales dependerá de su visualización en el ámbito jurídico y tributario, algo que no compete en exclusiva a la inspección turística. Donde sí puede resultar positiva la consideración de los usuarios de arrendamientos temporales como turistas es en el ámbito de los estudios turísticos. Estas personas no computan oficialmente como turistas, por lo que pueden distorsionar las políticas públicas en la materia, que no tienen en cuenta esta variable. Sin embargo, y al igual que en los casos anteriores, debe desligarse la solución de este problema a su mera categorización legal como turista, ya que para una correcta planificación de la política turística es indiferente que los turistas contabilizados lo sean jurídicamente o únicamente a efectos estadísticos, como podría hacerse con estos arrendatarios.

Por lo que se refiere a la posición contraria a su configuración como establecimientos de alojamiento turístico, ésta es sostenida esencialmente por

\footnotetext{
${ }^{9}$ En un porcentaje considerable de ocasiones, estos servicios se contratan y pagan a través de Internet en terceros países, por lo que los ingresos directos generados por esta actividad no revierten en el territorio donde radica la vivienda.
} 
particulares y por empresas de intermediación inmobiliaria o turística que gestionan este tipo de contratos. Al margen de consideraciones puramente fiscales o económicas, esta posición argumenta que se trataría de una iniciativa auspiciada por el lobby hotelero con la intención de reducir la competencia.Por otro lado, consideran desproporcionado exigir a estas viviendas unos servicios y estándares de calidad similares a los establecidos para los establecimientos turísticos regulares, ya que los particulares no tienen ni la capacidad económica ni de gestión necesarias para ello. Por su parte, el sector inmobiliario considera que las residencias particulares y las viviendas de uso turístico pueden convivir sin mayores problemas, sin que sea por tanto necesario establecer ninguna diferenciación legal ${ }^{10}$.

\section{La modificación de la Ley de Arrendamientos Urbanos: la exclusión del} alquiler turístico.

Como se ha adelantado, la figura del arrendamiento por temporada ha sido utilizada tradicionalmente por los propietarios de viviendas particulares para instrumentar su relación jurídica conlos usuarios turísticos. Para terminar con esta situación y solventar en lo posible los problemas analizados en los epígrafes anteriores, el legislador estatal ha decidido modificar la LAU para introducir un nuevo epígrafe en su artículo 5, excluyendo expresamente la actividad turística de su ámbito de aplicación. En concreto, señala la nueva letra $e$ de este artículo que "Quedan excluidos del ámbito de aplicación de esta Ley: [...] La cesión temporal de uso de la totalidad de una vivienda amueblada y equipada en condiciones de uso inmediato, comercializada o promocionada en canales de oferta turística y realizada con finalidad lucrativa, cuando esté sometida a un régimen específico, derivado de su normativa sectorial".

La renovada LAU excluye, pues, de su ámbito de aplicación -imposibilitando su utilización en adelante por los propietarios particulares- toda actividad de naturaleza eminentemente turística, estableciendo para ello una serie de requisitos o indicadores:

\footnotetext{
10 “Está avisado: su casa no es un hotel”, El País, Lluís Pellicer, 1 de mayo de 2013, edición digital.
} 
a) Que se alquile la totalidad de la vivienda. Se excluye, por tanto, el alquiler de piezas sueltas de la vivienda, generalmente habitaciones.El legislador ha considerado que este tipo de sub-arrendamiento de vivienda no es merecedor de la consideración como alquiler turístico debido a su carácter residual y naturaleza ajena al propio fenómeno turístico, por lo que continua en el ámbito civil.

b) Que esté en condiciones de uso inmediato. Es decir, que esté debidamente amueblada y equipada para realizar las actividades propias de la vida ordinaria. En este caso entiende el legisladorque una vivienda sin muebles no reúne las condiciones necesarias para su disfrute turístico. Lógicamente los turistas no se desplazan transportando los muebles y enseres necesarios para establecerse temporalmente en el lugar de destino, por lo que los arrendadores de viviendas sin amueblar en ningún caso podrán ser considerados turistas.

c) Comercializados o promocionados en canales de oferta turística.¿Quiere esto decir que las viviendas arrendadas prescindiendo de estos canales no serán considerados alquileres turísticos? Los canales de oferta turística habituales para este tipo de arrendamiento son las agencias inmobiliarias, las agencias de viajes y, muy especialmente, Internet. El legislador parece establecer el uso de estos canales como un requisito y no como un mero indicio de su naturaleza turística. Por esta razón, y salvo interpretación legal o jurisprudencial en contrario, los arrendamientos concertados directamente entre propietario y usuario turístico -escasos en la práctica- podrán seguir considerándose como arrendamientos por temporada, como hasta ahora, y eludir la regulación turística. Esta interpretación parece ser contraria al espíritu de la norma, pero el texto de la Ley es claro y no deja lugar a dudas sobre la obligatoriedad de este requisito.

d) Con finalidad lucrativa, excluyéndose los préstamos de uso -gratuitos- que en ningún caso tienen la consideración de arrendamientos, por lo que no pueden estar amparados por la LAU o la normativa turística.

e) Sometido a un régimen específico de su normativa sectorial. Es decir, que la normativa turística prevea el arrendamiento de viviendas particulares como una actividad turística y la regule expresamente, estableciendo un régimen jurídico 
específico para esta actividad. No debe atenderse únicamente a las categorías establecidas por la normativa sectorial -autonómica-, cuyas denominaciones pueden hacer pensar que este tipo de arrendamientos están tratados de forma específica en la normativa turística, sino a la naturaleza misma de dichas categorías. Es decir, únicamente podrá considerarse que una Comunidad Autónoma cumple con este último requisito cuando ha previsto en su normativa turística una categoría específica para el arrendamiento de viviendas particulares consideradas como tales, individualmente, (y nunca como parte de conjuntos o complejos turísticos), y además prevé el resto de requisitos previstos en la LAU. Si no es así, los propietarios de viviendas particulares podrán seguir utilizando la figura del arrendamiento por temporada hasta que el legislador autonómico desarrolle esta previsión. Actualmente, la gran mayoría de Comunidades Autónomas carecen de regímenes específicos para el arrendamiento de viviendas particulares a turistas en su normativa sectorial, por lo que la exclusión introducida con la modificación de la LAU aún no es operativa en la mayor parte del territorio nacional.

Para explicar mejor este último requisito resulta conveniente acudir a unejemplo práctico. Para ello se va a utilizar la regulación existente en la Comunidad Autónoma andaluza. La Ley 13/2011, de 23 de diciembre, del Turismo en Andalucía, regula en su artículo 44 la figura de los apartamentos turísticos, configurándolos como establecimientos destinados a prestar el servicio de alojamiento turístico, compuestos por un conjunto de "unidades de alojamiento" que cuenten con mobiliario e instalaciones adecuadas para la conservación, elaboración y consumo de alimentos y bebidas, y que cumplan los restantes requisitos establecidos reglamentariamente. Las unidades de alojamiento que integran estos establecimientos podrán ser apartamentos, villas, chalés, bungalós o inmuebles análogos, rigiendo en todo caso por el principio de unidad de explotación. Los apartamentos turísticos andaluces se clasifican en dos categorías: a) Edificios/complejos, queson aquellos establecimientos integrados por tres o más unidades de alojamiento que ocupan la totalidad o parte independiente de un edificio o de varios, disponiendo de entrada propia y, en su caso, ascensores y escaleras de uso exclusivo; y b) Conjuntos, queson aquellos establecimientos integrados por tres o más unidades de alojamiento ubicadas en un mismo inmueble o grupo de inmuebles, contiguos o no, ocupando sólo una parte de los mismos.En ambos casos son necesarias 
tres o más "unidades de alojamiento" (además de otros requisitos de independencia de instalaciones en el caso de edificios/complejos), por lo que las viviendas particulares individualmente consideradas en ningún caso estarán reguladas por la normativa sectorial andaluza. Las viviendas particulares arrendadas a turistas únicamente quedarán sujetas a la normativa sectorial cuando un mismo propietario posea tres o más de éstas dedicadas a la actividad turística, y en todo caso siempre que se respete el principio de unidad de explotación, que conforme a la Ley andaluza obliga a que la gestión de todas la unidades alojativascorresponda a un mismo titular ${ }^{11}$. Fuera de este caso los propietarios particulares podrán seguir utilizando la LAU, hasta tanto el legislador andaluz no establezca un régimen turístico específico para estos inmuebles.

Un caso diferente lo constituyen las casas rurales y viviendas turísticas de alojamiento rural. En ambos casos se trata de figuras que no establecen un número mínimo de unidades alojativas, por lo que éstas resultan de aplicación a los arrendamientos de viviendas particulares a usuarios turísticos individualmente consideradas. Si una de estas viviendas ubicadas en el medio rural cumple con los requisitos establecidos reglamentariamente al efecto deberá quedar sometida obligatoriamente a la normativa sectorial turística y por consiguiente excluida automáticamente del ámbito de la LAU. Esta situación no se ha alterado un ápice con la modificación de la LAU, puesto que desde la entrada en vigor de la normativa sectorial cualquier alojamiento cuyas características coincidan con las previstas en alguna modalidad turística deberá regirse obligatoriamente por aquélla, so pena de ser considerada actividad clandestina, excluyéndose en todo caso la posibilidad de acudir a la normativa civil.

Para el resto de Comunidades Autónomas habrá que estar al tratamiento que éstas hacen de las viviendas particulares arrendadas individualmente a turistas por sus titulares. Únicamente en el caso de que la normativa sectorial prevea expresamente esta figura con las mismas características que las previstas en la LAU, quedará excluida la utilización del esta norma y de la figura del arrendamiento por temporada. En caso

\footnotetext{
${ }^{11}$ La obligatoriedad de este principio permitiría considerar fraude de ley la dispersión de la gestión de tres o mas de estos inmuebles con la intención de evitar la aplicación de la normativa turística.
} 
contrario podrá seguir utilizándose sin problema alguno a la espera de una eventual modificación de su normativa sectorial.

\section{La adaptación de la normativa turística a las nuevas previsiones de la LAU. El modelo catalán y valenciano.}

A día de hoy muy pocas Comunidades Autónomas han previsto expresamente en su normativa sectorial los arrendamientos turísticos excluidos de la LAU.Entre los modelos más acabados y acordes con la previsión de la nueva LAU destaca la Comunidad Autónoma catalana, cuya avidez recaudatoria sobre los establecimientos turísticos precede en el tiempo y supera incluso a la estatal. Este territorio previó un régimen específico para el alquiler turístico de viviendas particulares con anterioridad incluso a la modificación de la LAU. Se trata del Decreto 159/2012, de 20 de noviembre, de establecimientos de alojamiento turístico y de viviendas de uso turístico. Esta norma diferencia entre alojamientos turísticos en general, que incluye la figura del apartamento turístico, cuyas características -independencia de instalaciones, carácter profesional, servicios complementarios al alojamiento- excluyen su aplicación al objeto de este estudio; y las viviendas de uso turístico, cuya configuración como viviendas particulares aisladamente consideradas permiten su exclusión del régimen tradicional de la LAU.

Para el ejecutivo catalán son merecedoras de un tratamiento específico en su normativa sectorial aquellas viviendas cedidas por su propietario, directamente o indirectamente, a terceros, de forma reiterada y a cambio de contraprestación económica, para una estancia de temporada, en condiciones de inmediata disponibilidad. Al igual que hace la LAU, es necesario que la vivienda sea arrendada en su totalidad, pero incluye dos limitaciones no previstas por aquélla: que no se superen los 31 días de alquiler por año y que sea cedida un mínimo de dos veces, es decir, que se realicen al menos dos alquileres diferentes que en ningún caso pueden superar conjuntamente el máximo de días marcado.Todo lo que exceda este límite temporal o no alcance el número mínimo de alquileres diferenciados quedará fuera de la normativa 
turística, pudiendo utilizarse el arrendamiento por temporada de la LAU. La modificación introducida en ésta no exige en ningún caso la exclusión total de los arrendamientos turísticos de viviendas particulares, únicamente prevé la exclusión de su ámbito si éstos han sido objeto de regulación específica por la normativa sectorial, por lo que, a pesar de lo restrictivo de la norma catalana, ésta puede continuar sin necesidad de ampliar su objeto el tiempo que estime conveniente.

Para todas aquellas viviendas que pasen a ser consideradas como de uso turístico, por cumplir las previsiones del Decreto 159/2012, se les exigirá una serie de requisitos de naturaleza técnica y administrativa para poder ejercer legalmente esta actividad. En caso contrario no podrán realizar esta actividad de ninguna manera, pasando a ser considerada clandestina ${ }^{12}$. Entre los requisitos de carácter técnico o relativos a la propia vivienda, el decreto catalán establece los siguientes:

a) Disponer de cédula de habitabilidad (para lo que habrá que acudir a la normativa específica).

b) Cumplir las condiciones técnicas y de calidad exigibles a las viviendas (¿implica esta exigencia una cláusula de progreso implícita?).

c) No contener más plazas que las indicadas en la cédula de habitabilidad.

d) Estar amuebladas y disponer de losenseres necesarios para su uso en relación al número de plazas declaradas.

e) Disponer de un número de teléfono del "responsable" de la vivienda ante los usuarios turísticos, que en cualquier caso debe estar siempre disponible de forma inmediata.

f) Prestar garantía de servicio de asistencia y mantenimiento de la vivienda.

En cuanto a los requisitos administrativo para la explotación turística de la vivienda, son los siguientes:

\footnotetext{
${ }^{12}$ Sus propietarios únicamente podrán utilizar el arrendamiento por temporada de la LAU, pero sólo para contratos de duración superior a los 31 días.
} 
a) Comunicación previa ante el Ayuntamientopor parte de su propietario y, en su caso, de la persona gestora del mismo, que puede ser tanto persona física como jurídica. Los extremos que deben ponerse en conocimientos de la Administración harán referencia a los datos de la vivienda, su capacidad máxima, la identidad del propietario y su teléfono, los datos de la empresa encargada de su mantenimiento ${ }^{13}$, una declaración responsable de que dispone de cédula de habitabilidad, los datos del gestor (si existe) y una declaración responsable de que dispone de titulo suficiente de su propietario.

b) Obligación de comunicar cualquier alteración de los datos facilitados al Ayuntamiento (sin límite temporal para ello, por lo que habrá de estarse a las circunstancias del caso concreto).

c) Acceso de la inspección turística sin necesidad de comunicación previa ni intervención judicial, ya que estos inmuebles nunca podrán ser consideradosdomicilio de su propietario. En tal sentido,los Ayuntamientos podrán solicitar el auxilio de la Generalidad de Cataluña en labores de inspección relacionadas con la actividad de vivienda de uso turístico.

d) Inscripción en un Registro específicode ámbito autonómico (Registro de Turismo de Cataluña), a iniciativa de los Ayuntamientos mediante extranet.

e) Disponer en todo momento de hojas oficiales de quejas/reclamaciones a disposición de los usuarios dentro de la propia vivienda ${ }^{14}$.

f)Exhibir en un lugar visible y fácilmente accesible para las personas usuarias:

- El rótulo informativo de la disponibilidad de las hojas oficiales de queja, reclamación y denuncia.

- El número de teléfono previsto en el apartado 2 de este artículo.

\footnotetext{
13 No parece razonable exigir obligatoriamente la contratación de una empresa encargada del mantenimiento de la vivienda teniendo en cuenta la escasa ocupación temporal de ésta por temporada (recuérdese el máximo de 31 días) y la posibilidad de que sea el directamente su propietario el que realice las labores de mantenimiento. Sin embargo, la norma catalana es taxativa a este respecto.

14 Para evitar las molestias y restricción de libertad que supone tener que acudir al domicilio del propietario u oficinas de la empresa gestora para reflejar las quejas por parte de los usuarios.
} 
- Número de registro de entrada en el Ayuntamiento de la comunicación previa de inicio de actividad.

g)Remitir a la Dirección General de la Policía la información sobre los usuarios (normativa de seguridad ciudadana).

En cualquier caso, no en todos los casos son admisibles las viviendas de uso turístico. El ejecutivo catalán veta la existencia de estos establecimientos a) cuando esté prohibida la actividad turística por los usos del sector en los que se encuentre, por lo que habrá que acudir a los instrumentos de ordenación urbanística del municipio; y b) Cuando lo prohíban los Estatutos de la Comunidad de Propietarios (propiedad horizontal) debidamente inscritos en el Registro de la Propiedad, lo que en la práctica suele ocurrir en muy escasas ocasiones ${ }^{15}$.Y por lo que respecta a su eventual categorización turística, la norma catalana considera que este tipo de alojamientos no tiene la entidad necesaria para exigirla desde el ámbito público, por lo que se limita a permitir que estas viviendas acudan, si lo estiman conveniente, a cualquier sistema privado de categorización turística.

Frente a posibles incumplimientos por parte del propietario de la vivienda, el decreto catalán sanciona cualquier falta o inexactitud en la comunicación a presentar por éste con la imposibilidad de ejercer la actividad desde que se tenga constancia de ello. Esto, además, sin perjuicio del régimen sancionador previsto en la normativa sectorial turística, de vivienda, de consumo y municipal de aplicación. Además, se fija una responsabilidad de tipo solidaria entre propietario y gestor para aumentar la garantía de pago de tales sanciones.

Por último, se prevé un sencillo mecanismo que pretende proteger al resto de propietarios del inmueble en el que se ubica la vivienda de uso turístico. En aquellos casos en los que elusuario atente contra las reglas básicas de la convivencia o incumpla

\footnotetext{
${ }^{15}$ La Ley de Propiedad Horizontal (art. 17.6) exige la unanimidad del total de los propietarios que, a su vez, representen la mayoría de las cuotas de participación, para la modificación de los Estatutos que rigen una Comunidad de Propietarios. Por esta razón, en el caso de que éstos no contuviesen la aludida prohibición de forma expresa (además de estar debidamente inscritos en el Registro de la Propiedad correspondiente), no podrá hacerse a posteriori sin contar con la totalidad de los propietarios, incluido el eventual propietario interesado en esta actividad, por lo que, en la practica, limitar esta posibilidad una vez que existen viviendas en uso turístico resulta inviable (al menos por esta vía).
} 
ordenanzas municipales dictadas a tal efecto, el titular o gestor de la vivienda deberá requerir, en el plazo de veinticuatro horas, a éste para que abandone la vivienda. Se trata de una medida harto voluntarista pero con una efectividad cuestionable, que reduce los plazos en relación con las medidas aplicables en sede judicial a un arrendatario ordinario, que igualmente está sujeto a las reglas de convivencia de la comunidad de propietarios y al resto del Ordenamiento Jurídico, pero que no prevé las consecuencias ni para el propietario que no cumple con su obligación de requerir al huésped problemático ni para éste si opta por hacer caso omiso del requerimiento del dueño de la vivienda. En cualquier caso, y teniendo en cuenta que la LAU acepta excluir este tipo de arrendamientos de su ámbito de aplicación y lo reenvía a la normativa sectorial, podrá recurrirse a las técnicas aplicables a los establecimientos de alojamiento turístico en caso de huéspedes problemáticos (v.gr. destrozos o ruidos en una habitación de hotel), ya que han dejado de ser arrendamientos a todos los efectos. Su nueva naturaleza es indiscutiblemente turística, y las medidas para garantizar la convivencia en los inmuebles en los que se ubican deben ser las propias de esta actividad, más rápidas y eficaces que las previstas en el ámbito civil para los arrendamientos urbanos.

El modelo catalán se cierra con un sistema de incentivos a favor de los Ayuntamientos para que aumenten su celo en relación con estos alojamientos. Se intenta asegurar su colaboración haciéndoles partícipe de un porcentaje de la tasa turística cobrada por cada pernoctación que tenga lugar en su término municipal. Se pretende, de esta forma, acabar con uno de los mayores problemas que tradicionalmente han existido en la lucha contra la opacidad en los arrendamientos urbanos: la falta de colaboración por parte de los Ayuntamientos implicados, que debían soportar los gastos de la inspección sin obtener un beneficio directo por ello.

Frente al modelo catalán, el Decreto 92/2009, de 3 de julio, del Consell, por el que se aprueba el reglamento regulador de las viviendas turísticas denominadas apartamentos, villas, chalés, bungalows y similares, y de las empresas gestoras, personas jurídicas o físicas, dedicadas a la cesión de uso y disfrute, en el ámbito de la Comunitat Valenciana, configura un régimen similar a aquél con varios años de adelanto, más amplio en cuanto a su objeto pero menos preciso y exigente. Este decreto regula la cesión de viviendas particulares para usos turísticos, pero también las 
empresas que gestionan estos alquileres y los canales de comercialización ${ }^{16}$, estableciendo además una categorización obligatoria ${ }^{17}$, algo desechado por la normativa catalana. También contiene algunas previsiones sobre información al usuario, precios o depósitos, además de la posibilidad de resolver el contrato de alojamiento por mal comportamiento del huésped, tal y como ocurre en el resto de normativa sobre establecimientos de alojamiento turístico. En cuanto al régimen sancionador se remite a la Ley general de turismo de esta Comunidad Autónoma.

El decreto valenciano exige, al igual que la LAU y el Decreto catalán, la habitualidad en la actividad para ser objeto de esta norma, si bien no establece plazos concretos. En este caso se establece una serie de criterios subjetivos como son su cesión por empresas gestoras de viviendas turísticas, la prestación de servicios propios de la industria hotelera (limpieza, cambio de lencería, custodia de maletas, lavandería, reparaciones y mantenimiento y similares) o la utilización de canales de comercialización turística. En todos estos casos será preceptiva la comunicación a la Administraciónde la dedicación al uso turístico de la vivienda, que incluirá una serie de datos básicos como localización, número de plazas y requisitos necesarios para su categorización $^{18}$, además del cumplimiento de los requisitos establecidos para la categoría solicitada. Una vez recibida la comunicación pertinente, la Administración procederá a inscribir estas viviendas en un registro público específico.

Por lo que respecta a las empresas gestoras de este tipo de viviendas, únicamente serán consideradas como tales las que gestionen al menos cinco viviendas, por lo que quedarán fuera de la normativa sectorial aquéllos alquileres de viviendas realizados por empresas que no alcancen este umbral. No queda claro si la norma prohíbe la existencia de empresas que gestiones menos de cinco viviendas, debiendo hacerse directamente por sus propietarios o cediéndose a otras de mayor tamaño, o excluye la aplicación del

\footnotetext{
${ }^{16}$ En este aspecto, se exige por ejemplo que en toda publicidad relativa a estas viviendas se incluya obligatoriamente tanto el número de registro de las citadas viviendas como su categoría.

${ }^{17}$ Estableciendo tres categorías: superior, primera y estándar, cuyos requisitos están fijados en el anexo de la norma.

${ }^{18}$ A lo que se le sumará una declaración responsable de su titular en lo que se deje constancia expresa de la disponibilidad del inmueble y de la concurrencia en la misma de los requisitos exigidos por el Decreto para su clasificación en la categoría solicitada.
} 
Decreto a estas viviendas, amparándose para ello en la LAU y la figura del arrendamiento por temporada, algo que no parece acorde con la lógica del mismo.

Frente a la inflexibilidad del régimen jurídico catalán, el Decreto valenciano excluye parcialmente de su aplicación a aquellas personas jurídicas que cedan directamente -es decir, sin recurrir a canales de comercialización turística- una sola vivienda sin prestar servicios propios de la industria hotelera. El propietario quedará eximido de la obligación de comunicar a la Administración la dedicación de su vivienda al uso turístico y las eventuales modificaciones producidas en éstas. A pesar de ello, el Decreto seguirá siendo de obligado cumplimiento en lo que se refiere a los requisitos exigidos, al menos, para la categoría básica, y al resto de prescripciones contenidas en el mismo. Además, el titular de la vivienda podrá solicitar voluntariamente su clasificación, para lo que será obligatorio el régimen de comunicaciones citado. Pero lo que resulta más interesante es que el propietario que opta por no comunicar a la Administración el uso turístico de la vivienda deberá advertir esta circunstancia a los usuarios para que sean conscientes de que se trata de alojamientos cuyas dotaciones y servicios no han sido verificados por la Administración turística.Se puede criticar esta opción del ejecutivo valencianoen el sentido de resultar cuanto menos ingenuo exigir una serie de requisitos que no van a ser corroborados por la Administración, dejando a la buena voluntad del propietario de la vivienda el cumplimiento de unas exigencias onerosas que no tienen por qué generarle beneficios netos. En cualquier caso, el ejecutivo valenciano establece un sistema mixto que excluye en todo caso la aplicación del contrato de arrendamiento por temporada previsto en la LAY, pero que gradúa la exigencia al propietario y la intervención administrativa en función del número de viviendas explotadas turísticamente por su titular y los canales de comercialización utilizados.

Tanto el catalán como el valenciano son dos posibles modelos para el resto de Comunidades Autónomas que aún no han establecido un régimen jurídico específico para las viviendas particulares arrendadas a usuarios turísticos en su normativa sectorial. Ambos son perfectamente compatibles con la nueva redacción de la LAU, que como se ha señalado no exige en ningún momento la exclusión automática y total de estas viviendas del ámbito de los arrendamientos urbanos, sino que establece únicamente una 
posibilidad para el legislador autonómico, que sigue siendo libre para elegir entre considerar aquéllas alojamientos turísticos como los tradicionales o bien viviendas ordinarias sujetas al régimen tradicional del arrendamiento por temporada. En última instancia dependerá de que los decisores públicos hagan suyas las razones expuestas a favor de su regulación administrativa o, por el contrario, consideren más conveniente mantener el régimen jurídico vigente hasta el momento.

\section{Una experiencia del Derecho comparado: Argentina.}

La controversia en torno al uso de viviendas particulares en la actividad turística no es exclusiva de España. Un ejemplo de ello puede encontrarse en la República Argentina, donde en los últimos años se ha vivido un debate similar con consecuencias también muy parecidas ${ }^{19}$. La situación de partida sin embargo era bastante diferente, ya que al parque de viviendas particulares para alquiler turístico gestionadas directa o indirectamente por sus propietarios hay que sumar la proliferación de edificios completos e independientes, con servicios propios de la figura del apartahotel español (recepción, servicio de habitaciones, restaurante, etc), que oficialmente constan como comunidades de vecinos ordinarias cuando realmente prestan un servicio de alojamiento turístico de media y alta categoría, dedicándose la totalidad de sus viviendas a esta actividad, algo que no existe en España ${ }^{20}$. Como en el caso español se ha utilizado tradicionalmente la Ley 23.091, de 20 de septiembre de 1984,deLocaciones Urbanas (equivalente a la LAU), pero progresivamente han ido surgiendo normas locales que

\footnotetext{
19 Sobre esta materia vid., entre otros, FRESNO, G., "Hotelería en la ciudad de Buenos Aires. Competencia desleal: análisis y propuestas para su erradicación”, Observatorio del Derecho del Turismo, Universidad de Buenos Aires, agosto de 2013; y OLIVA, J., "Mercado de inversión en apartamentos turísticos en Buenos Aires", en Tecnohotel: revista profesional para la hostelería y restauración, $\mathrm{n}^{\circ} 434$, 2007, pág. 10.

20 Este tipo de establecimientos turísticos encubiertos se concentran primordialmente en la Ciudad Autónoma de Buenos Aires y su área metropolitana. Como ejemplo de ellas pueden citarse establecimientos como Apart Abasto, Concord Recoleta Suites o Forcadell Apartments.
} 
intentaban reconducir esta actividad al ámbito turístico ${ }^{21}$. Entre ellas destaca las recientes Leyes de la ciudad autónoma de Buenos Aires 4.631, de 4 de julio, de 2013, de Regulación de Alojamientos Turísticos; y 4.632, del mismo día, de Registración de Propiedades de Alquiler Temporario Turístico, que, sin modificar la norma estatal sobre arrendamientos urbanos, establecen sendas medidas fundamentales: obliga a que los edificios que se alquilan en su totalidad y cuentan con servicios hoteleros se habiliten como lo que son (hoteles o apartahoteles, en función de sus características), cumpliendo con todos sus requisitos y obligaciones; y establece la obligatoriedad de que las viviendas particulares dedicadas a la actividad turística ${ }^{22}$ se inscriban en el Registro de Propiedades de Alquiler Turístico Temporario y cumplan ciertos requisitos de calidad y seguridad $^{23}$.Sin embargo, esta última obligación solamente rige para aquellos particulares que sean titulares de tres o más viviendas o empresas que gestionen un número igual de éstas, quedando fuera las demás. La normativa argentina se encuentra, pues, en un momento inmediatamente anterior a la última reforma española, en el que

\footnotetext{
${ }^{21}$ Entre otras, Mendoza, Río Negro, Bariloche, Puerto Madryn, Colón, Alta Gracia y Santa Cruz.

${ }^{22}$ Esta Ley 4.632 entiende como alquiler temporal para fines turísticos aquél que [...] brinda alojamiento a turistas en viviendas amuebladas de manera habitual por un período no menor a una pernoctación y no mayor a los 6 meses" (art. 3).
}

${ }^{23}$ EL art. 11 de la Ley 4.632 establece que "El locador deberá suscribir con carácter de Declaración Jurada un acta en la que conste el cumplimiento de las siguientes obligaciones: 1. Contar con la registración conforme lo normado en el capítulo segundo de la presente y en la reglamentación que en consecuencia se dicte. 2. Cumplir con las disposiciones de seguridad, las técnico-constructivas y las referentes a personas con discapacidades y/o movilidad reducida de acuerdo a la normativa vigente en la Ciudad Autónoma de Buenos Aires. 3. Exhibir en lugar visible de la entrada de la unidad o de la recepción del inmueble una copia del Certificado de inscripción al registro, establecido en el Artículo 6, asignada por la autoridad de aplicación cuyas características serán determinadas por la normativa reglamentaria. 4. Incluir el número de inscripción en el registro que crea el artículo 6 en toda reserva y publicidad en la que se ofreciere el inmueble en locación, cualquiera fuere el medio o soporte en el que se realice, así como en el contrato a suscribir y en el formulario prenumerado que se adjuntará al mismo. 5. Constituir en el contrato y en el formulario del artículo octavo un domicilio especial en el ámbito de la Ciudad Autónoma de Buenos Aires a los efectos de toda notificación que la autoridad de aplicación, las partes o cualquier organismo o repartición pública deba efectuar. 6. Informar al huésped al momento de efectuarse la reserva los servicios ofrecidos y las condiciones de los mismos. Asimismo, se deberá comunicar el horario de ingreso y egreso y la tarifa a aplicar a la estadía. 7. Notificar la transferencia, venta o cesión del inmueble, el cambio de destino o el cese de su ofrecimiento como propiedad de alquiler turístico temporario en los plazos y términos que establezca la reglamentación. 8. Brindar a los huéspedes las comodidades y servicios en las fechas y condiciones pactadas y a los que se obligara en la contratación suscripta. 9. En las unidades se deberá exhibir en material impreso: a) condiciones y políticas de los servicios ofrecidos, propios y/o tercerizados con sus correspondientes precios vigentes. $b$ ) Plano de evacuación para caso de incendio o catástrofes. c) Plano del sistema de iluminación auxiliar del inmueble cuando correspondiere. d) Listado de números telefónicos para llamados de emergencias. 10. Notificar al Consorcio de Propietarios de la existencia de un inmueble que sea dado en locación temporaria con fines turísticos. 11. Informar al locatario de la existencia del Reglamento de Copropiedad y poner una copia a su disposición." 
habitualmente quedaban fuera los propietarios con menos de tres viviendas dedicadas a esta actividad. Se trata, en definitiva, de dos modelos convergentes pero que avanzan a velocidades diferentes, debido seguramente a la diferente experiencia en la materia de ambos países, mucho más dilatada en el caso español.

\section{Reflexión final.}

Si bien no resultaba necesario modificar la LAU desde un punto de vista estrictamente jurídico, ya que la normativa sectorial puede excluir de facto los arrendamientos turísticos del ámbito del arrendamiento por temporada precisando su contenido, sí que ha proporcionado una mayor claridad y seguridad jurídica a los propietarios de éstos, que a partir de este momento, y en función de lo que decidan la diferentes Comunidades Autónomas, van a saber exactamente cual es la normativa que rige su actividad dependiendo de sus caracteres concretos. Dicho de otro modo, el concepto de arrendamiento por temporada es un concepto de perfiles difusos en el que tenía cabida el arrendamiento turístico siempre y cuando la normativa sectorial no lo hubiese precisado, tal y como ocurrió en las Comunidades valenciana y catalana. Al no estar expresamente previsto ni excluido, la normativa sectorial podía acotar su contenido y extraerlo del ámbito de la LAU, sin necesidad de modificar el marco jurídico original.En cualquier caso, parece un acierto esta clarificación y sistematización normativa, sin contar con la "revolución" que supone la consideración de estos inquilinos como turistas y, por ende, consumidores, con el aumento de derechos y de vías de protección de los mismos que esto lleva implícito.

Por otro lado, y a la espera de lo que hagan el resto de Comunidades Autónomas, parece que la opción del legislador autonómico no es en ningún caso equiparar estas

viviendas con un establecimiento de alojamiento turístico ordinario, lo cual no sería lógico ya que no es esa su naturaleza. Las viviendas particulares dan satisfacción a un sector de la demanda turística que no coincide con el resto, ni por necesidades ni por 
duración de su estancia, por lo que no constituyen una competencia real para el resto de establecimientos tradicionales. Tampoco sería pertinente cargar al propietario individual con los requisitos y obligaciones inherentes a un establecimiento hotelero, ya que no cuentan ni con la capacidad económica ni organizativa para ello. Pero sí parece necesario establecer ciertos requisitos de calidad y seguridad que garanticen, al menos en teoría, un nivel mínimo de satisfacción turística, tal y como hacen las normas sectoriales analizadas.

En cualquier caso, debe advertirse de la enorme dificultad que conllevará el complemento de esta regulación habida cuenta de la gran cantidad de viviendas de esta naturaleza y la escasez de medios con los que cuenta la Administración para su control. Sin desconocer que la visibilidad que Internet proporciona a esta actividad es un instrumento a favor de la Administración, resultará prácticamente imposible el control periódico de los requisitos exigidos a estos inmuebles más allá de su efectiva inscripción en los registros públicos. Las expectativas deben mantenerse bajas si no se quiere correr el riesgo de que éstas queden pronto defraudadas, sobre todo en lo que atañe a ámbitos ajenos al estrictamente turístico, como el tributario o la seguridad ciudadana. Y es que, por su propia naturaleza dispersa y opaca, el control efectivo de las viviendas particulares de uso turístico es prácticamente imposible. Quizá una buena solución sería la instauración de un régimen sancionador lo suficientemente estricto como para "motivar" a los propietarios a hacer emerger a la superficie su actividad si las razones expuestas por el legislador no le convencen suficientemente. 